\title{
Ensino em Fisioterapia no Brasil: como inquietar o estudante e despertar o seu protagonismo?
}

\author{
Erivaldo Santos de Lima \\ Acadêmico de Fisioterapia, Universidade Estadual de Ciências da Saúde de Alagoas (UNCISAL) \\ 凶erivaldolimah@gmail.com
}

Recebido em 25 de janeiro de 2020

Aceito em 11 de agosto de 2020

\begin{abstract}
Resumo:
O presente ensaio versa sobre algumas inquietações e reflexões no que concerne o ensino em fisioterapia e seu papel frente a promoção de protagonismo discente, principalmente para o fortalecimento do Sistema Único de Saúde (SUS). Estrutura-se em quatro partes: na primeira, o autor situa o contexto disparador das inquietações, na segunda, contextualiza a figura do Fisioterapeuta enquanto docente e apresenta alguns dos seus desafios, na terceira, apresenta as contribuições do movimento estudantil e dos estágios de vivência para a formação em saúde, na quarta e última parte, une as peças do quebra cabeça respondendo a pergunta em questão.

Palavras-chave: Educação Superior, Docentes, Fisioterapia, Empoderamento para a Saúde.

\section{Physiotherapy Teaching in Brazil: how to disturb the student and awaken his protagonism?}

\begin{abstract}
:
This essay deals with some concerns and reflections regarding physiotherapy teaching and its role in the promotion of student protagonism, especially for the strengthening of the Unified Health System (SUS). It is structured in four parts: in the first, the author places the triggering context of the concerns, in the second, contextualizes the figure of the Physical Therapist as a teacher and presents some of his challenges, in the third, presents the contributions of the student movement and the stages of experience For health education, in the fourth and last part, it joins the pieces of the puzzle by answering the question in question.

Keywords: Education Higher, Faculty, Physical Therapy Specialty, Empowerment for Health.

\section{Enseñanza de fisioterapia en Brasil: ¿cómo molestar al alumno y despertar su protagonismo?}

\section{Resumen:}

Este ensayo aborda algunas preocupaciones y reflexiones sobre la enseñanza de fisioterapia ysupapel en la promoción del protagonismo de los estudiantes, especialmente para el fortalecimiento del Sistema Único de Salud (SUS). Se estructura en cuatro partes: en la primera, el autor coloca el contexto desencadenante de las preocupaciones, en la segunda, contextualiza la figura del fisioterapeutacomo maestro y presenta algunos de sus desafíos, en la tercera, presenta las contribuciones del movimiento estudiantil y las etapas de la experiencia para la educación sanitaria, en la cuarta y última parte, se une a las piezas del rompecabezas que responde a la pregunta en cuestión.

Palabras clave: Educación Superior, docentes, Fisioterapia, Empoderamiento para la Salud. 


\section{O CONTEXTO DISPARADOR}

Durante quatro anos participando de forma ativa no Movimento Estudantil em Fisioterapia (MEFISIO) ao nível local, regional e nacional por intermédio da Executiva Nacional de Estudantes de Fisioterapia (ENEFI) e Centro Acadêmico de Fisioterapia da Universidade Estadual de Ciências da Saúde de Alagoas (UNCISAL) bem como de espaços como o projeto de Vivências e Estágios na Realidade do SUS (VER-SUS) na condição de vivente, facilitador e de comissão organizadora em Alagoas, muitas foram as inquietações no que diz respeito ao ensino em Fisioterapia e sua capacidade de transformar o cenário da saúde brasileira.

A ENEFI é uma entidade estudantil que representa os estudantes de Fisioterapia nacionalmente fundada no ano de 2002 em João Pessoa/PB. Ao longo do tempo, a Executiva passou por momentos de desarticulação e de rearticulação. São suas pautas prioritárias o mundo do trabalho, a educação e a saúde (SANCHES et al., 2014).

A entidade defende um ensino de qualidade que seja alinhado ao Sistema Único de Saúde (SUS). Nesse sentido, reconhece iniciativas como o VER-SUS como sendo indutoras de transformações no que concerne ao modelo de ensino e consequente desenvolvimento de competências, habilidades e atitudes que dialoguem com as reais necessidades de saúde da população, por outro lado, não isenta a Universidade de seu papel na formação acadêmica e cidadã (SANCHES et al., 2014).

O VER-SUS é um projeto do Ministério da Saúde que foi criado em parceria com o movimento estudantil com o objetivo despertar o protagonismo dos (futuros) profissionais do SUS. Para isso, se utiliza de um processo imersivo em que os participantes além de conhecer e discutir de forma aprofundada sobre a realidade do SUS, aprendem também sobre o trabalho interprofissional, a convivência em equipe e sobre as diversas possibilidades do fazer saúde (BRASIL, 2004).

Um ensino voltado para as necessidades de saúde da população não é uma pauta levantada apenas pelo MEFISIO, tampouco pelo VER-SUS. As Diretrizes Curriculares Nacionais dos Cursos de Graduação de Fisioterapia, instituídas em 2002, por exemplo, apontam para a necessidade de uma formação em que o egresso seja capaz de atuar nos três níveis de atenção a saúde, bem como, capaz de enxergar os problemas da sociedade, 
nesse sentido, percebe-se o Fisioterapeuta enquanto sujeito político, crítico e reflexivo (BRASIL, 2002).

Nas vivências pelo Brasil, a citar em eventos com os Encontros Regionais e Nacionais de Estudantes de Fisioterapia (EREFISIOs e ENAFISIOs) e Conselho Regional de Estudantes de Fisioterapia (COREFI), VER-SUS, entre tantas discussões nesses espaços em momentos formais e(ou) informais, o sentimento que os estudantes compartilham (principalmente os que estão tendo o primeiro contato com a experiência) é de indignação sobre como que só nesses espaços se percebem protagonistas.

Esse protagonismo perpassa a formação acadêmica bem como seu alinhamento com as necessidades de saúde da população brasileira. A impressão que transmitem é de que foram educados em um ambiente virtual no qual nunca permitiram se emocionar, se contagiar e entender que são parte de um Sistema que necessita de profissionais que sejam capazes de retirar seu escudo branco para ir em lugares que a graduação talvez nunca tenha ido.

Nesse sentido, uma lacuna se abre e nos convida a refletir sobre o que a graduação em Fisioterapia (não) está fazendo para promover protagonismo aos seus estudantes e de que forma as experiências do MEFISIO e do VER-SUS podem contribuir com esse debate/reflexão.

\section{A FIGURA DO FISIOTERAPEUTA DOCENTE E OS SEUS DESAFIOS}

O Fisioterapeuta docente teve como base para sua prática profissional em meados da década de 70 - quando começou a surgir os primeiros cursos de fisioterapia no Brasil - a figura do médico, visto que naquela época em sua maioria os docentes dos cursos de fisioterapia até então existentes eram médicos. Isso favoreceu e ainda favorece um ensino fragmentado, especializado e que tem a reabilitação como sua identidade profissional (SILVA et al., 2015).

A Resolução do Conselho Nacional de Educação (CNE) e Câmara de Educação Superior (CES) que institui as Diretrizes Curriculares Nacionais dos Cursos de Graduação em 
Fisioterapia “definem os princípios, fundamentos, condições e procedimentos da formação de fisioterapeutas [...] para aplicação em âmbito nacional na organização, desenvolvimento e avaliação dos projetos pedagógicos dos Cursos de Graduação em Fisioterapia" (BRASIL, 2002, p. 11).

Tal resolução, coloca como competências e habilidades gerais necessárias ao Fisioterapeuta a atenção à saúde, a tomada de decisões, a comunicação, liderança e administração e ainda a educação permanente (BRASIL, 2002). Em um contexto de mudanças nas Diretrizes Curriculares Nacionais dos Cursos de Graduação em Fisioterapia, a Associação Brasileira de Ensino em Fisioterapia (ABENFISIO) vem desempenhando um papel crucial mobilizando docentes pelo Brasil e suscitando debates que contribuem com o (re)pensar das práticas cotidianas.

Efetivar o que preconiza a Diretriz Curricular é um desafio para o Fisioterapeuta Docente, isso porque sua experiência e saber técnico são imprescindíveis para sua atuação enquanto docente, embora não sejam suficientes (TREVISO; COSTA, 2017).

É consenso que este profissional necessita de competências pedagógicas para atuação enquanto docente (BARROS; DIAS, 2016). A não competência pedagógica para a docência no contexto saúde favorece a perpetuação de metodologias tradicionais de ensino, que acarreta um ensino que vai de encontro com o que se preconiza pela Diretriz Curricular Nacional (HERMES; CUTOLO; MAESTRELLI, 2016).

Almeida (2015) aponta para a necessidade de um ensino voltado à promoção/ao desenvolvimento da autonomia dos envolvidos para que de tal forma se possa obter um aprendizado mais crítico, reflexivo e não limitado a realidade do ambiente acadêmico. Nesse sentido, para Oliveira et al. (2015) a pedagogia tradicional favorece a manipulação e a manutenção do poder, isso porque se caracteriza por um modelo de verticalização no qual o discente assume apenas a figura de receptor de informações.

Verifica-se que tal modelo não favorece a mudança de práticas no contexto saúde (OLIVEIRA et al., 2015). Para Ferracini e Ruiz-Moreno (2017, p. 25) “O momento formativo atual exige do docente que ultrapasse o modelo transmissivo, assumindo o papel de facilitador e mediador do processo de aprendizagem, visando à democratização das relações sociais." 
Uma alternativa eficaz a conjuntura do ensino na saúde são as metodologias ativas de ensino. A pedagogia da problematização enquanto metodologia ativa, contribui com a formação de sujeitos críticos, reflexivos e autônomos favorecendo a superação dos desafios e necessidades do SUS (OLIVEIRA et al., 2015).

\title{
CONTRIBUIÇÕES DO MOVIMENTO ESTUDANTIL, VER-SUS E O PROTAGONISMO DISCENTE
}

O movimento estudantil brasileiro tem uma estreita relação com o Sistema Único de Saúde, assim, pode-se citar o marco histórico que culminou no SUS que temos hoje: a reforma sanitária.

Sabe-se, que a formação de recursos humanos para o SUS é o maior desafio desse setor, nesse sentido, e em decorrência do modelo hospitalocêntrico, verifica-se um desprestígio das disciplinas de saúde coletiva nas Universidades. Esse desafio é percebido e alvo de discussão também pelos estudantes através do movimento estudantil (BRASIL, 2004).

A juventude do movimento estudantil junto de outros atores sociais, com o objetivo de aproximar a formação universitária das grandes pautas sociais, deram origem entre outras iniciativas, ao VER-SUS (TORRES, 2013). Este projeto tem sido objeto de estudos nas mais diversas localidades do país (MARANHÃO, 2013). Sobre um dos impactos dessas vivências e estágios Torres (2013, p.11) afirma que:

\begin{abstract}
A intervenção fundamental provocada pelos estágios de vivência é provocar incômodo, desestabilizar os pré-conceitos, as pré-concepções e permitir ao estudante novas formas de experimentar o ensino, a partir de metodologias pouco utilizadas na formação tradicional.
\end{abstract}

A proposta deu certo. A participação no VER-SUS enquanto vivente é tida como um marco na formação acadêmica, política e cidadã. Nesse sentido, os incômodos e afetações que ele provoca são capazes de potencializar o protagonismo estudantil, como também, o 
docente, de gestores e usuários, tudo isso corrobora com o fortalecimento do SUS (MARANHÃO; MATOS, 2018).

O projeto acontece em caráter de imersão, ou seja, os participantes (estudantes, profissionais e integrantes de movimentos sociais) convivem $24 \mathrm{~h}$ durante aproximadamente duas semanas em contextos formativos diversos e hospedados geralmente em espaços como escolas, universidades e outros (MARANHÃO; MATOS, 2018). As atividades são facilitadas por outros estudantes ou profissionais que já participaram de edições anteriores do projeto.

Projetos como o VER-SUS aproximam o ensino do serviço de saúde num contexto multi e interdisciplinar, isso faz com que os atores envolvidos ressignifique a sua compreensão do que é saúde a partir de uma intersecção entre as diversas ciências, entre o saber popular e o saber científico, entre a realidade e o imaginário endossado pelo poder hegemônico, além disso, tem capacidade de provocar reflexões sobre qual é o real papel da Universidade, favorecendo dessa forma uma aprendizagem significativa (LEAL et al., 2015; WEBER et al., 2016; BURILLE et al., 2013).

Para Valadares (2011, p. 36) aprender significativamente acontece quando o indivíduo:

[...] consegue relacionar, de maneira substantiva (não literal) e não arbitrária, a nova informação com uma estrutura de conhecimento específica que faz parte integrante da sua estrutura cognitiva prévia. Esta é singular, idiossincrásica e complexa, e nela constam as afirmações e os conceitos que o indivíduo previamente aprendeu, mas onde também está plasmada toda a componente afetiva do indivíduo e o resultado de todas as suas ações e vivências.

O projeto facilita o desenvolvimento de competências e habilidades como a escuta (na perspectiva do trabalho multiprofissional) e o acolhimento (SOUZA et al., 2012). Esses instrumentos são essenciais ao cuidado em saúde. Para alguns estudantes, essa mudança de paradigmas pode acontecer de maneira tardia, já no final da graduação, para outros, de forma precoce, logo nos primeiros períodos. Independente de quando, o como, pode transformar a jornada acadêmica por completo. 
Sobre o processo de ensino-aprendizagem Leal et al. (2015, p. 369) afirmam que este:

[...] pode e deve romper a fragmentação dos saberes e práticas em saúde, permitindo identificar as correlações entre os saberes, a complexidade da vida e dos problemas de saúde da população. Além disso, é importante reconhecer que estas experiências devemser ampliadas, e suas estratégias operacionais introduzidas nos espaços curriculares sempre que coerentes comos objetivos da universidade pública e da formação emsaúde ordenada pelo SUS.

Talvez seja esse o grande segredo de experiências como o VER-SUS, o rompimento com tudo aquilo que está posto. Valença et al. (2014, p. 835) relatam como contribuições desse projeto para a formação em saúde:

[...] a articulação ensino/ serviço/comunidade; a união entre teoria e prática ao longo das atividades; a utilização de metodologias ativas no processo ensino/aprendizagem; a problematização de situações e contextos sociais;a sensibilização diante das necessidades sociais e de saúde da população; a oportunidade de vivenciar a realidade dos usuários do SUS; a reflexão crítica sobre a realidade; o protagonismo discente e o estímulo à participação de movimentos estudantis e projetos de extensão.

Contribuições como as citadas também são proporcionadas por Executivas de Curso, Centros e Diretórios Acadêmicos da área de saúde. O movimento estudantil vem lançando mão de metodologias problematizadoras, pautadas na horizontalidade de saberes, na sensibilização e escuta qualificada, ao tempo que assim como o VER-SUS insere os estudantes em contextos e discussões secundarizadas na formação universitária em saúde, um exemplo disso, são os espaços de saúde mental promovido pela ENEFI e eventos como o Conversa de FISIO protagonizados pelo CAFISIO da UNCISAL (LIMA et al., 2017; WANDERLEY et al., 2018). 


\section{UNINDO AS PEÇAS DO QUEBRA CABEÇA}

Espaços como os promovidos pelo movimento estudantil brasileiro bem como os estágios e vivências na realidade do SUS não devem assumir o papel formativo que cabe a universidade, por outro lado, fica claro as contribuições deles para que as instituições de ensino e os docentes repensem um ensino que seja tão potente quanto.

É mais do que necessário um ensino que rompa as grades do currículo e que seja capaz de promover a consciência cidadã dos discentes bem como o seu protagonismo frente às demandas sociais e de saúde. Isso será possível quando os cursos de graduação em Fisioterapia começarem a criar espaços reais de imersão nesses contextos, para além da teorização dos conteúdos em sala de aula.

Diante disso, alguns palpites do que a graduação em Fisioterapia (não) está fazendo para promover protagonismo aos seus estudantes, o primeiro trata-se da pouca horizontalidade de saberes no cotidiano. Essa tal de hierarquia tem potencial para deixar o estudante cego, surdo e mudo. Ele vai enxergar muito pouco além do que o docente transmite, vai ouvir muito pouco o que a sociedade grita no que se refere as necessidades de saúde e por último, pode se calar diante de tudo.

A falta de empatia se soma a essa lista. Faz-se necessário que o docente enxergue o que o estudante traz em sua bagagem para além do seu saber, mas também seus anseios, suas emoções, as barreiras sociais que enfrentam para se manterem na Universidade, suas dificuldades financeiras, sua saúde, sobretudo a mental. A relação discente-docente não deve ser um cabo de guerra. $\mathrm{O}$ docente não deve reproduzir e justificar sua prática - muitas vezes opressora - com a sua vivência quando discente. Como ensinar a um estudante que ele deve ser empático quando não se é? Como formar um Fisioterapeuta em consonância aos princípios do Sistema Único de Saúde, destaco a equidade, quando este princípio passa longe das práticas cotidianas?

Ainda nesse sentido, destaca-se a pouca entrega docente, a percepção é de que falta presença na universidade e na sala de aula, pertencimento à profissão docente. Além disso, é perceptível a indiferença docente, um estado de não crítica, sobre si e sobre a sociedade que o cerca. Vale salientar que não há a intenção de generalizar, mas de destacar as impressões do autor de acordo com o seu contexto. 
As tentativas inadequadas de promover o diálogo do estudante (academia) com as demandas sociais (povo) também figuram essa lista. É preciso ir à rua numa perspectiva de encarar a sociedade como sujeito que tem a ensinar e não apenas como sujeito de estudo/pesquisa que tem a aprender, promover a horizontalidade de saberes também fora do ambiente universitário, dessa forma, cria-se uma ponte para possibilidades de transformações no cenário do ensino em saúde.

Acrescenta-se ainda, o uso de metodologias tradicionais, o desestímulo à participação de movimentos sociais e estudantis, o desencorajamento a extensão universitária socialmente referenciada. Criar espaços que favoreçam o protagonismo discente na formação em saúde, é sem dúvidas criar possibilidades de fortalecimento do Sistema Único de Saúde.

\section{AGRADECIMENTOS}

A Executiva Nacional de Estudantes de Fisioterapia (ENEFI), ao Centro Acadêmico de Fisioterapia (CAFISIO/UNCISAL) - Gestão 2016, 2017 e 2018, ao Diretório Central dos Estudantes Nise da Silveira (DCE/UNCISAL) - Gestão 2015, 2016 e 2017, a todos os viventes, comissão organizadora e facilitadores do VER-SUS Alagoas - Vivência Arapiraca (2016.1) e Vivência Maceió (2016.2).

\section{REFERÊNCIAS}

ALMEIDA, Hélio Mangueira de. A didáti ca no ensino superior: práticas e desafios. 2015.

BARROS, Conceição de Maria Pinheiro; DIAS, Ana Maria Iorio. A formação pedagógica de docentes bacharéis na educação superior: construindo o Estado da Questão. Revista Educação em Questão, v. 54, n. 40, p. 42-74, 2016. Disponível em: <https://periodicos.ufrn.br/educacaoemquestao/article/view/9848>. Acesso em 06 Jun 2019.

BISPO JUNIOR José Patrício. Formação em fisioterapia no Brasil: reflexões sobre a expansão do ensino e os modelos de formação. Hist. cienc. saude-Mangui nhos, Rio de Janeiro, v. 16, n. 3, p. 655- 668, Set. 2009. Disponível em:<http://dx.doi.org/10.1590/S0104-59702009000300005>. Acesso em 10 Ago 2019.

BRASIL. Conselho Nacional de Educação. Diretrizes curriculares nacionais do curso de graduação em fi si oterapia. Diário Oficial da União, Brasília, DF, 4 mar. 2002.

BRASIL. Ministério da Saúde. Secretaria de Gestão do Trabalho e da Educação na Saúde. Departamento de Gestão de Educação na Saúde. VER-SUS Brasil: Caderno de Textos. Brasília: Ministério da Saúde; 2004. 
BURILLE, Andreia; MATOS, Izabella Barison; FILHO, Carlos Alberto Rodrigues Morrudo; MELLO, Claudia Cássia Silva et al. Do VER-SUS: do que é, do que foi e do que ficou. Revista Eletrônica de Comuni cação, Informação e Inovação em Saúde, v. 7, n. 4,2013. Disponível em:

<https://www.reciis.icict.fiocruz.br/index.php/reciis/article/view/523 >. Acesso em 06 Jun 2019.

FERRACINI, Lucio Guilherme; RUIZ-MORENO, Lidia. Dramatização psicodramática na formação docente de profissionais da saúde. Revista Brasileira de Psicodrama, v. 25, n. 1, p. 18-27, 2017. Disponível em: $<$ http://pepsic.bvsalud.org/scielo.php?script=sci_arttext\&pid=S0104-53932017000100003>. Acesso em 20 Jun 2019.

HERMES, Fabiola Chesani; CUTOLO, Luiz Roberto Agea; MAESTRELLI, Sylvia Regina Pedrosa. A Concepção de Estudantes de Fisioterapia que Participam do Ensino Baseado em Problemas sobre o Processo Saúde-Doença. Rev. bras. educ. méd, v. 40, n. 4, p. 627-634, 2016. Disponível em: <http://dx.doi.org/10.1590/198152712015v40n4e01202015>. Acesso em 06 Jun 2019.

LEAL, Juliana Alves Leite; MELO, Cristina Maria Meira; VELOSO, Rafaela Braga Pereira; JULIANO, Iraildes Andrade. Novos espaços de reorientação para formação em saúde: vivências de estudantes. InterfaceComuni cação, Saúde, Educação, v. 19, p. 361-371, 2015. Disponível em: < https://doi.org/10.1590/180757622014.0107>. Acesso em 10 Ago 2019.

LIMA, Erivaldo Santos de; OLIVEIRA, Jackelyne Soares de; BALBINO, Lucas Pereira; SILVA, Dannyelle Shyrley dos Santos da et al. CONVERSA DE FISIO: HORIZONTALIDADE COMO FERRAMENTA DE AMPLIAÇÃO DO OLHAR DO ESTUDANTE DE FISIOTERAPIA. CADERNOS DE EDUCAÇÃO, SAÚDE E FISIOTERAPIA, v. 4, n. 8, 2017. Disponível em: <http://revista.redeunida.org.br/ojs/index.php/cadernos-educacao-saudefisioter/article/view/1605>. Acesso em 14 Set 2019.

MARANHÃO, Thaís; MATOS, Izabella Barison. Vivências no Sistema Único de Saúde (SUS) como marcadoras de acontecimento no campo da Saúde Coletiva. Interface-Comuni cação, Saúde, Educação, v. 22, p. 55-66, 2017. Disponível em:<http://dx.doi.org/10.1590/1807-57622016.0091>. Acesso em 10 Ago 2019.

MARANHÃO, Thaís. Vivências e estágios na realidade do Sistema Único de Saúde: um "garimpo" bibliográfico. Revista Eletrôni ca de Comuni cação, Informação e Inovação em Saúde, v. 7, n. 4, 2013. Disponível em: <https://www.reciis.icict.fiocruz.br/index.php/reciis/article/view/529>. Acesso em 20 Jun 2019.

MENDES, Flavio Martins de Souza; FONSECA; Karina de Andrade; BRASIL, Julia Alves; DALBELLO-ARAÚJO, Maristela. Ver-Sus: relato de vivências na formação de Psicologia. Psicologia Ciência e Profissão, v. 32, n. 1, p. 174-187, 2012. Disponível em: <http://dx.doi.org/10.1590/S1414-98932012000100013>. Acesso em 06 Jun 2019.

OLIVEIRA, Dafylla Kelly Silva; QUARESMA, Viviana do Socorro Maciel; PEREIRA, Jane de Almeida; CUNHA, Emmanuel Ribeiro. A arte de educar na área da saúde: experiências com metodologias ativas. Humanidades \& Inovação, v. 2, n. 1, 2015. Disponível em: <https://revista.unitins.br/index.php/humanidadeseinovacao/article/view/60>. Acesso em 20 Jun 2019.

SANCHES, Vinicius Santos; FERNANDES, Janainny Magalhães; JÚNIOR, José Félix de Brito; MACHADO, Alisson Eduardo Ferreira et al. CARTA DE CAMPO GRANDE-CONSELHO NACIONAL DOS ESTUDANTES DE FISIOTERAPIA. CADERNOS DE EDUCAÇÃO, SAÚDE E FISIOTERAPIA, v. 1, n. 2, 2014. Disponível em: <http://revista.redeunida.org.br/ojs/index.php/cadernos-educacao-saude-fisioter/article/view/335/pdf_7>. Acesso em 20 Jul. 2019.

SILVA, Grasiela Garrett da; ESPÍNDOLA, Daniela Simoni; LAZZARI, Daniele Delacanal; BACKES, Vânia Marli Schubert et al. Formação inicial de professores na enfermagem, fisioterapia e odontologia. Saúde \& Transformação Social/Health \& Social Change, v. 6, n. 3, p. 118-128, 2015. Disponível em: <http://stat.saudeetransformacao.incubadora.ufsc.br/index.php/saudeetransformacao/article/view/3038>. Acesso em 06 Jun 2019. 
TORRES, Odete Messa. Os estágios de vivência no Sistema Único de Saúde do Brasil: caracterizando a participação estudantil. Revista Eletrôni ca de Comuni cação, Informação e Inovação em Saúde, v. 7, n. 4, 2013. Disponível em : < http://dx.doi.org/10.3395/reciis.v7i4.571>. Acesso em 20 Jun 2019.

TREVISO, Patrícia; COSTA, Bartira Ercília Pinheiro da. Percepção de profissionais da área da saúde sobre a formação em sua atividade docente. Texto \& Contexto Enfermagem, v. 26, n. 1, p. 1-9, 2017. Disponível em: <http://dx.doi.org/10.1590/0104-07072017005020015>. Acesso em 20 Jul. 2019.

VALADARES, Jorge. A teoria da aprendizagem significativa como teoria construtivista. Aprendi zagem Significativa em Revista, v. 1, n. 1, p. 36-57, 2011. Disponível em:

<http://www.if.ufrgs.br/asr/artigos/Artigo_ID4/v1_n1_a2011.pdf>. Acesso em 20 Jul. 2019.

VALENÇA, Cecília Nogueira; GERMANO, Raimunda Medeiros; MALVEIRA, Fernanda Aparecida Soares; AZEVÊDO, Lorena Mara Nóbrega de et al. Articulação teoria/prática na formação em saúde e a realidade do Sistema Único de Saúde [Articulating theory and practice in health education in face of the Unified Health System]. Revista Enfermagem UERJ, v. 22, n. 6, p. 830-835, 2014. Disponível em: <https://www.epublicacoes.uerj.br/index.php/enfermagemuerj/article/view/16451>. Acesso em 06 Jun 2019.

WANDERLEY, Geísa Dias; LIMA, Erivaldo Santos de; JÚNIOR, José Félix de Brito; SILVA, Lucas Oliveira da et al. FISIOTERAPIA E SAÚDE MENTAL NO MOVIMENTO ESTUDANTIL: RESSIGNIFICANDO OLHARES E QUALIFICANDO A FORMAÇÃO. CADERNOS DE EDUCAÇÃO, SAÚDE E FISIOTERAPIA, v. 5, n. 10, 2018. Disponível em: <http://revista.redeunida.org.br/ojs/index.php/cadernos-educacao-saudefisioter/article/view/2201>. Acesso em 14 Set 2019.

WEBER, Aldair; TOMBINI, Larissa Hermes Thomas; COLLISELLI, Liane; ALBRECHT, Cristiane Carla et al. Vivências e estágios na realidade do SUS (VER-SUS) e a formação profissional em saúde: relato de experiência. Extensio: Revista Eletrônica de Extensão, v. 13, n. 23, p. 112-122, 2016. Disponível em: <https://doi.org/10.5007/18070221.2016v13n23p112>. Acesso em 06 Jun 2019.

$(c)$ EY

Este trabalho está licenciado com uma Licença Creative Commons - Atribuição 4.0 Internacional. 